\title{
Plasma homocysteine levels associated with a corrected QT interval
}

\author{
Zhao Li ${ }^{1} \mathbb{D}$, Xiaofan Guo', Guozhe Sun ${ }^{1}$, Liqiang Zheng ${ }^{2}$, Yingxian Sun ${ }^{*}$, Yamin Liư ${ }^{3}$ and Maria Roselle Abraham³
}

\begin{abstract}
Background: Little is known about the relationship between homocysteine (Hcy) levels and the QT interval. We examined the association of different Hcy levels with corrected QT (QTc) intervals in a general population.

Methods: Plasma levels of Hcy were assessed in a population-based study of 7002 participants 35 years of age and older from 2012 to 2013. Twelve-lead ECGs were performed on all participants and analyzed automatically.

Results: The distribution of Hcy levels was determined for an entire population after the data were grouped into quartiles (Q1: <=11.1 umol/L; Q2: 11.1-13.8umol/L; Q3: 13.8-18.2 umol/L; Q4 > 18.2 umol/L). The mean value of the QTc interval in each quartile was $433.2 \pm 23.8 \mathrm{~ms}, 430.0 \pm 24.6 \mathrm{~ms}, 429.2 \pm 24.5 \mathrm{~ms}$ and $430.6 \pm 25.7 \mathrm{~ms}$. Multiple logistic regression analyses showed that, compared with the second quartile, and after fully adjusting for potential confounding factors, the odds for QTc $>440 \mathrm{~ms}$ in the first and fourth quartile increased $(P<0.05)$, (OR: 1.23, 95\% Cl: 1.05-1.43 for Q1; OR: 1.40, 95\% Cl: 1.19-1.65 for Q4).
\end{abstract}

Conclusions: QTc interval was associated with the Hcy level in this general population.

Keywords: Homocysteine, Corrected QT interval, Metabolic syndrome, Cardiovascular disease

\section{Background}

Homocysteine (Hcy) is a non-protein amino acid that contains sulfur and is derived from the essential amino acid methionine [1, 2]. Previous studies reported that Hcy was associated with cardiovascular diseases such as aortic atherosclerosis, hypertension, coronary artery disease and acute myocardial infarction [3-9].

The QT interval is the electrocardiographic manifestation of ventricular depolarization and repolarization. A prolonged QT interval is closely related to ventricular arrhythmias, which can cause sudden cardiac death (SCD) [10]. In mice, the QT interval was found to be affected by Hcy levels [11]. Recent studies determined that Hcy was also related to arrhythmias and SCD, which indicated the possibility that Hcy was associated with cardiac electrophysiology [7, 8, 12-15]. However, few studies focused on the relationship between Hcy and the QTc interval in the general population. Detection of the QTc interval can help predict the risk of cardiovascular disease (CVD) events

\footnotetext{
* Correspondence: yxsun@mail.cmu.edu.cn

${ }^{1}$ Department of Cardiology, the First Hospital of China Medical University,

155 Nanjing North Street, Heping District, Shenyang 110001, People's

Republic of China

Full list of author information is available at the end of the article
}

[16-19]. Therefore, in this study, we evaluated plasma Hcy levels and the QTc interval in a general population to determine whether there is an association between Hcy levels and the QT interval.

\section{Methods \\ Study population}

The methods used were described in previous studies [20, 21-23]. From January 2012 to August 2013, a representative sample of individuals at least 35 years of age was selected to describe the prevalence, incidence and natural history of cardiovascular risk factors in rural areas of the Liaoning Province, located in Northeast China. This study followed a random cluster-sampling scheme in 2 counties (Zhangwu and Liaoyang County) and one town was randomly selected from each county. From each town,8-10 rural villages were randomly selected, for a total of 26 rural villages. Participants that were pregnant, had malignant tumors and or mental disorders were excluded from this study. All eligible permanent residents aged at least 35 years of age from each village (total 8365) were invited to participate in the study, and response rate was $85.3 \%$. We used baseline data 
from each participant with a complete data set sampled from Zhangwu and the Liaoyang counties, and a final sample size of 7002 (3260 men and 3742 women, Additional file 1). The study was approved by the Ethics Committee of China Medical University (Shenyang, China). All procedures were performed in accordance with ethical standards. Written consent was obtained from all participants after they had been informed of the objectives, benefits, medical terms and the personal information confidentiality agreement. If the participants were illiterate, we obtained written informed consent from their proxies.

\section{Data collection and measurements}

The data collection and methods of measurements used in this study are as described in previous studies [22]. Data on demographic characteristics, lifestyle risk factors, dietary habits, family income, history of heart disease and medication used two weeks prior to the study were obtained through an interview with a standardized questionnaire. A central steering committee with a subcommittee for quality control was established. Dietary patterns were assessed using each participant's recall of foods eaten during the previous year. The questionnaire included inquiries regarding the average consumption of several food items per week. The reported consumption was approximately quantified in terms of grams per week (i.e., vegetable consumption: rarely $=3,<1000 \mathrm{~g}=2,1000$ $2000 \mathrm{~g}=1, \geq 2000 \mathrm{~g}=0$; meat consumption including red meat, fish, and poultry: rarely $=0,<250 \mathrm{~g}=1,250-$ $500 \mathrm{~g}=2, \geq 500 \mathrm{~g}=3$ ). Each participant was assigned a special diet score ranging from 0 to 6 calculated by the addition of their vegetable and meat consumption scores. Higher diet score values indicated higher meat consumption, lower vegetable consumption and greater adherence to a Westernized diet, while lower values indicated adherence to a Chinese diet. Similar methods for calculating diet scores can be found in the ATTICA study [24].

Blood pressure was measured three times at 2-min intervals after at least $5 \mathrm{~min}$ of rest according to The American Heart Association protocol. Blood pressure measurements were obtained using a standardized, automatic, electronic sphygmomanometer (HEM-907; Omron), which had already been validated according to the British Hypertension Society protocol [25]. The participants were advised to avoid caffeinated beverages or exercise for at least $30 \mathrm{~min}$ before the measurement. During the measurement, the participants were seated with their arms supported at heart level. The mean of three blood pressure (BP) measurements was calculated and used in all analyses. Body mass index (BMI) was calculated as weight in kilograms divided by the square of the height in meters.
For all participants, fasting blood samples were collected in the morning after at least $12 \mathrm{~h}$ of fasting. Blood samples were obtained from the antecubital vein using BD Vacutainer tubes containing EDTA (Becton, Dickinson and Co., Franklin Lakes, NJ, USA). Serum was subsequently isolated from the whole blood, and all serum samples were frozen at $-20{ }^{\circ} \mathrm{C}$ for testing at a central, certified laboratory. Fasting plasma glucose (FPG), total cholesterol (TC), lowdensity lipoprotein cholesterol (LDL-C), high-density lipoprotein cholesterol (HDL-C), triglyceride (TG), serum potassium and magnesium and other routine blood biochemical indexes were analyzed enzymatically on an auto-analyzer (Olympus AU640 AutoAnalyzer; Olympus Corp., Kobe, Japan).

Plasma Hcy levels were measured by an enzyme cycling method using a Hitachi 7020 Automatic Analyzer (Hitachi). All laboratory equipment was calibrated, and blind, duplicate samples were used.

Standard 12-lead ECGs were conducted with a MAC 5500 (GE Healthcare, Little Chalfont, Buckinghamshire, UK) as previously described [22], and analyzed automatically with the MUSE Cardiology Information System, Version 7.0.0 (GE Healthcare). ECG parameters, including the QT interval, were measured automatically. The QT interval is measured from the earliest detection of depolarization in any lead to the latest detection of repolarization in any lead. Since the QT interval is influenced by heart rate, it is necessary to adjust heart rate for QT correction [26]. In this study, the QTc interval was corrected for the heart rate using the Bazett formula, which is the most common method [27-29]. Population were classified in two groups: one group included participants whose QTc intervals exceeding $440 \mathrm{~ms}$, the other group included participants whose QTc intervals equal or less than $440 \mathrm{~ms}$ [30-32].

\section{Statistical analysis}

Descriptive statistics were calculated for all variables, including continuous variables (expressed as the mean values and standard deviations) and categorical variables (expressed as numbers and proportions). Differences among categories were evaluated using the Student's $t$ test, ANOVA, non-parametric tests, or the $x^{2}$-test. Scheffe method was used to adjust for multiple hypothesis tests when conducting pairwise comparisons of the QTc responses by homocysteine quartile. Multivariable logistic regression analyses were used to identify independent associations between Hcy quartiles, other factors, and QTc $>440 \mathrm{~ms}$ in different models. Odds ratios (ORs) and corresponding 95\% confidence intervals (CIs) were calculated. Linear regression was also used to test the association between Hcy level and QTc interval. All statistical analyses were performed 
using SPSS Version 17.0 software, and $P$ values less than 0.05 were considered to be statistically significant.

\section{Results}

The present study of 7002 participants consisted of 3260 males and 3742 females. The mean participant age was 54 years, and the participant age ranged from 35 to
93 years. The mean Hcy level of the population was $17.32 \pm 12.34 \mathrm{umol} / \mathrm{L}$. Among the included population, 4695 and 2307 demonstrated QTc $\leq 440 \mathrm{~ms}$ and QTc $>440 \mathrm{~ms}$ The distribution of Hcy levels was determined for the entire population after the data were grouped into quartiles: Q1 contained Hcy levels $\leq 11.1 \mathrm{umol} / \mathrm{L}$; Q2 contained Hcy levels $>11.1 \mathrm{umol} / \mathrm{L}$ and $\leq 13.8 \mathrm{umol} /$

Table 1 Baseline characteristics of study population according to homocysteine level $(N=7002)$

\begin{tabular}{|c|c|c|c|c|c|}
\hline \multirow[t]{2}{*}{ Variables } & \multicolumn{4}{|c|}{ Homocysteine in quartiles $(\mathrm{mmol} / \mathrm{L})$} & \multirow[t]{2}{*}{$P$-value } \\
\hline & $\mathrm{Q} 1(\leq 11.1)$ & $\mathrm{Q} 2(>11.1$ and $\leq 13.8)$ & Q3 (>13.8 and $\leq 18.2)$ & Q4 (>18.2) & \\
\hline Age (year) & $49 \pm 9$ & $54 \pm 10$ & $56 \pm 10$ & $57 \pm 12$ & $<0.001$ \\
\hline Male gender & $300(17.2)$ & $710(40.8)$ & $1044(58.9)$ & $1206(69.4)$ & $<0.001$ \\
\hline Race of Han & $1625(92.9)$ & $1660(95.3)$ & $1669(94.2)$ & $1618(93.0)$ & 0.01 \\
\hline Smoking & $389(22.2)$ & 589 (33.8) & $751(42.4)$ & $908(52.2)$ & $<0.001$ \\
\hline Drinking & $217(12.4)$ & $365(21.0)$ & $498(28.1)$ & $525(30.2)$ & $<0.001$ \\
\hline Sleep duration $(\mathrm{h} / \mathrm{d})$ & $7.6 \pm 1.6$ & $7.3 \pm 1.6$ & $7.3 \pm 1.7$ & $7.5 \pm 1.8$ & 0.122 \\
\hline Diet score & $2.2 \pm 1.2$ & $2.2 \pm 1.2$ & $2.2 \pm 1.2$ & $2.3 \pm 1.1$ & $<0.001$ \\
\hline Education & & & & & $<0.001$ \\
\hline Primary school or below & $759(43.4)$ & $855(49.1)$ & $921(52.0)$ & $892(51.3)$ & \\
\hline Middle school & $830(47.5)$ & $723(41.5)$ & $677(38.2)$ & $703(40.4)$ & \\
\hline High school or above & $160(9.1)$ & $164(9.4)$ & $174(9.8)$ & $144(8.3)$ & \\
\hline Physical activity & & & & & $<0.001$ \\
\hline Low & $391(22.4)$ & $373(21.4)$ & $420(23.7)$ & $478(27.5)$ & \\
\hline Moderate & $1242(71.0)$ & $1259(72.3)$ & $1222(69.0)$ & $1176(67.6)$ & \\
\hline High & $116(6.6)$ & $110(6.3)$ & $130(7.3)$ & $85(4.9)$ & \\
\hline Family income (CNY/year) & & & & & $<0.001$ \\
\hline$\leq 5000$ & $222(12.7)$ & $284(16.3)$ & $342(19.3)$ & $395(22.7)$ & \\
\hline $5000-20,000$ & $993(56.8)$ & $978(56.1)$ & $1000(56.4)$ & $986(56.7)$ & \\
\hline$>20,000$ & $534(30.5)$ & $480(27.6)$ & $430(24.3)$ & $358(20.6)$ & \\
\hline $\mathrm{BMI}\left(\mathrm{kg} / \mathrm{m}^{2}\right)$ & $25.1 \pm 3.9$ & $24.7 \pm 3.7$ & $24.7 \pm 3.8$ & $24.8 \pm 3.7$ & 0.014 \\
\hline$W C(\mathrm{~cm})$ & $82.7 \pm 9.5$ & $83.4 \pm 10.0$ & $83.7 \pm 9.7$ & $84.4 \pm 10.1$ & $<0.001$ \\
\hline $\mathrm{SBP}(\mathrm{mmHg})$ & $138.9 \pm 23.4$ & $140.4 \pm 24.1$ & $144.9 \pm 24.3$ & $148.1 \pm 26.1$ & $<0.001$ \\
\hline $\mathrm{DBP}(\mathrm{mmHg})$ & $80.0 \pm 11.0$ & $81.0 \pm 11.8$ & $82.4 \pm 11.9$ & $83.7 \pm 12.5$ & $<0.001$ \\
\hline $\mathrm{FPG}(\mathrm{mmol} / \mathrm{L})$ & $5.9 \pm 1.9$ & $5.9 \pm 1.8$ & $5.8 \pm 1.4$ & $5.8 \pm 1.6$ & 0.002 \\
\hline $\mathrm{TC}(\mathrm{mmol} / \mathrm{L})$ & $5.0 \pm 1.1$ & $5.1 \pm 1.0$ & $5.1 \pm 1.0$ & $5.1 \pm 1.0$ & 0.009 \\
\hline $\mathrm{TG}(\mathrm{mmol} / \mathrm{L})$ & $1.6 \pm 2.1$ & $1.6 \pm 1.3$ & $1.7 \pm 1.4$ & $1.7 \pm 1.6$ & $<0.001$ \\
\hline LDL-C (mmol/L) & $2.8 \pm 0.8$ & $2.8 \pm 0.8$ & $2.8 \pm 0.7$ & $2.9 \pm 0.8$ & $<0.001$ \\
\hline $\mathrm{HDL}-\mathrm{C}(\mathrm{mmol} / \mathrm{L})$ & $1.5 \pm 0.4$ & $1.4 \pm 0.4$ & $1.4 \pm 0.4$ & $1.4 \pm 0.4$ & $<0.001$ \\
\hline Serum calcium (mmol/L) & $2.385 \pm 0.105$ & $2.382 \pm 0.102$ & $2.384 \pm 0.106$ & $2.396 \pm 0.105$ & $<0.001$ \\
\hline Serum potassium (mmol/L) & $4.189 \pm 0.340$ & $4.185 \pm 0.327$ & $4.185 \pm 0.329$ & $4.181 \pm 0.364$ & 0.72 \\
\hline Serum magnesium (mmol/L) & $0.866 \pm 0.073$ & $0.879 \pm 0.069$ & $0.883 \pm 0.073$ & $0.878 \pm 0.070$ & $<0.001$ \\
\hline History of heart disease ${ }^{a}$ & $138(7.9)$ & $180(10.3)$ & $196(11.1)$ & $163(9.4)$ & 0.01 \\
\hline Medication used ${ }^{b}$ & $936(53.5)$ & $933(53.6)$ & 979 (55.2) & $981(56.4)$ & 0.243 \\
\hline
\end{tabular}

Data are expressed as the mean \pm SD or as $\mathrm{n}(\%)$

Abbreviations: $C N Y$ China Yuan (1CNY = 0.157 USD), BMI body mass index, WC waist circumference, SBP systolic blood pressure, DBP diastolic blood pressure, FPG fasting plasma glucose, $T C$ total cholesterol, TG triglyceride, $L D L-C$ low-density lipoprotein cholesterol, $H D L-C$ high-density lipoprotein cholesterol

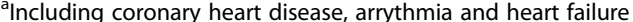

Indicating any self-reported medication used in the past two weeks.ps:P for category from chi-square; for continous from non-parametric test 
L; Q3 contained Hcy levels $>13.8$ umol/L and $\leq 18.2$ umol/L; and Q4 contained Hcy levels $>18.2$ umol/L. All variables are presented in the Table 1. Except for sleep duration, serum potassium, and medication used, all variables were significantly different across the four groups (all $p<0.05$ ).

Table 2 presents the baseline characteristics of the study population according to the QTc interval. Participants with QTc $>440 \mathrm{~ms}$ had a greater history of heart disease, lower physical activity and medication use, but lower rates of current smoking and drinking than those participants with QTc $\leq 440 \mathrm{~ms}$ (all $P<0.001$ ). Participants with QTc > $440 \mathrm{~ms}$ had higher BMI, SBP, DBP, FPG, TC, TG and LDL-C levels than those participants with QTc $\leq 440 \mathrm{~ms}$ (all $P<0.001$ ). No significant differences in serum calcium or magnesium were observed between the two groups. These results were consistent with the results obtained using the other two methods for QT correction.

Figures 1 and 2 illustrates the QTc intervals according to the Hcy quartiles in boxplot. Using the Bazett formula. Regardless of the correction method, higher mean QTc values were observed in Q1 and Q4, compared to those in Q2 $(p<0.01)$. There were no significant differences in the mean QTc values between Q2 and Q3. And, as shown in Fig. 3, the mean Hcy levels among participants who had QTc $>440 \mathrm{~ms}$ were higher than those who had QTc $\leq 440 \mathrm{~ms}(p=0.031)$.

Table 3 presents the relative odds of QT intervals. Using QTc intervals $>440 \mathrm{~ms}$ as dependent variables and Hcy quartile as independent variables, multivariable logistic regression analyses were applied to assess the association between Hcy levels and the QTc interval. Model 1 was adjusted for age and gender, model 2 was adjusted for factors in model 1 and lifestyle variables including education level, family income, diet score, sleep duration, current smoking status, drinking status, and physical activity, model 3 was adjusted for factors in model 2 and $\mathrm{CV}$ risk factors included body mass index, waist circumference, systolic blood pressure, diastolic blood pressure, and total cholesterol, and model 4 was a multivariable model adjusted for factors in model 3 and other factors which was considered could empirically affect the Qtc directly including serum calcium, potassium and magnesium, history of heart disease, and any medication which . As shown in Table 3, in model 3, the risk of QTc intervals $>440 \mathrm{~ms}$ in the first and fourth quartiles increased compared with those in the second quartile $(P<0.05)$. The odds ratio (OR) was 1.20 (95\% CI $1.03-$ $1.40)$ and 1.41 (95\% CI 1.120-2.01). We also considered serum calcium, potassium and magnesium, history of heart disease, and any medication into the final, fully adjusted model (model 4) to rule out their impacts. The results were consistent. Compared with the second quartile, the risk of QTc intervals $>440 \mathrm{~ms}$ in the first
Table 2 Baseline characteristics of study population according to QTC $(N=7002)$

\begin{tabular}{|c|c|c|c|}
\hline Variables & $\begin{array}{l}\text { QTc } \leq 0.44 \mathrm{~s} \\
(n=4695)\end{array}$ & $\begin{array}{l}\text { QTc }>0.44 \mathrm{~s} \\
(n=2307)\end{array}$ & $P$-value \\
\hline Age (year) & $53 \pm 10$ & $56 \pm 11$ & $<0.001$ \\
\hline Male gender & $2589(55.1)$ & $671(29.1)$ & $<0.001$ \\
\hline Race of Han & 4394 (93.6) & $2178(94.4)$ & 0.179 \\
\hline Smoking & 1905 (40.6) & $732(31.7)$ & $<0.001$ \\
\hline Drinking & $1250(26.6)$ & $355(15.4)$ & $<0.001$ \\
\hline Sleep duration $(\mathrm{h} / \mathrm{d})$ & $7.5 \pm 1.7$ & $7.4 \pm 1.7$ & 0.029 \\
\hline Diet score & $2.3 \pm 1.2$ & $2.1 \pm 1.1$ & $<0.001$ \\
\hline Education & & & $<0.001$ \\
\hline $\begin{array}{l}\text { Primary school } \\
\text { or below }\end{array}$ & $2162(46.0)$ & $1265(54.8)$ & \\
\hline Middle school & $2082(44.3)$ & $851(36.9)$ & \\
\hline $\begin{array}{l}\text { High school } \\
\text { or above }\end{array}$ & $451(9.6)$ & $191(8.3)$ & \\
\hline Physical activity & & & $<0.001$ \\
\hline Low & 969 (20.6) & $693(30.0)$ & \\
\hline Moderate & $3423(72.9)$ & $1476(64.0)$ & \\
\hline High & $303(6.5)$ & $138(6.0)$ & \\
\hline $\begin{array}{l}\text { Family income } \\
\text { (CNY/year) }\end{array}$ & & & $<0.001$ \\
\hline$\leq 5000$ & 778 (16.6) & $465(20.2)$ & \\
\hline $5000-20,000$ & $2664(56.7)$ & $1293(56.0)$ & \\
\hline$>20,000$ & $1253(26.7)$ & $549(23.8)$ & \\
\hline $\mathrm{BMI}\left(\mathrm{kg} / \mathrm{m}^{2}\right)$ & $24.6 \pm 3.7$ & $25.2 \pm 3.8$ & $<0.001$ \\
\hline WC (cm) & $83.1 \pm 9.8$ & $84.5 \pm 9.8$ & $<0.001$ \\
\hline $\mathrm{SBP}(\mathrm{mmHg})$ & $139.9 \pm 23.3$ & $149.6 \pm 26.3$ & $<0.001$ \\
\hline $\mathrm{DBP}(\mathrm{mmHg})$ & $80.6 \pm 11.2$ & $84.3 \pm 12.8$ & $<0.001$ \\
\hline FPG (mmol/L) & $5.7 \pm 1.4$ & $6.1 \pm 2.1$ & $<0.001$ \\
\hline TC $(\mathrm{mmol} / \mathrm{L})$ & $5.0 \pm 1.0$ & $5.2 \pm 1.1$ & $<0.001$ \\
\hline $\mathrm{TG}(\mathrm{mmol} / \mathrm{L})$ & $1.6 \pm 1.5$ & $1.9 \pm 1.8$ & $<0.001$ \\
\hline LDL-C (mmol/L) & $2.8 \pm 0.7$ & $2.9 \pm 0.8$ & $<0.001$ \\
\hline $\mathrm{HDL}-\mathrm{C}(\mathrm{mmol} / \mathrm{L})$ & $1.4 \pm 0.4$ & $1.4 \pm 0.4$ & 0.361 \\
\hline $\begin{array}{l}\text { Serum calcium } \\
(\mathrm{mmol} / \mathrm{L})\end{array}$ & $2.4 \pm 0.1$ & $2.4 \pm 0.1$ & 0.461 \\
\hline $\begin{array}{l}\text { Serum potassium } \\
(\mathrm{mmol} / \mathrm{L})\end{array}$ & $4.2 \pm 0.3$ & $4.1 \pm 0.3$ & $<0.001$ \\
\hline $\begin{array}{l}\text { Serum magnesium } \\
(\mathrm{mmol} / \mathrm{L})\end{array}$ & $0.9 \pm 0.1$ & $0.9 \pm 0.1$ & 0.057 \\
\hline $\begin{array}{l}\text { History of heart } \\
\text { disease }^{a}\end{array}$ & $383(8.2)$ & $294(12.7)$ & $<0.001$ \\
\hline Medication used ${ }^{b}$ & $2390(50.9)$ & $1439(62.4)$ & $<0.001$ \\
\hline
\end{tabular}

Data are expressed as the mean \pm SD or as $n$ (\%)

Abbreviations: $C N Y$ China Yuan (1CNY $=0.157$ USD), BMI body mass index, WC waist circumference, SBP systolic blood pressure, DBP diastolic blood pressure, FPG fasting plasma glucose, TC total cholesterol, TG triglyceride, $L D L-C$ lowdensity lipoprotein cholesterol, $H D L-C$ high-density lipoprotein cholesterol ancluding coronary heart disease, arrythmia and heart failure b Indicating any self-reported medication used in the past two weeks.ps:P for category from chi-square; for continous from non-parametric test 


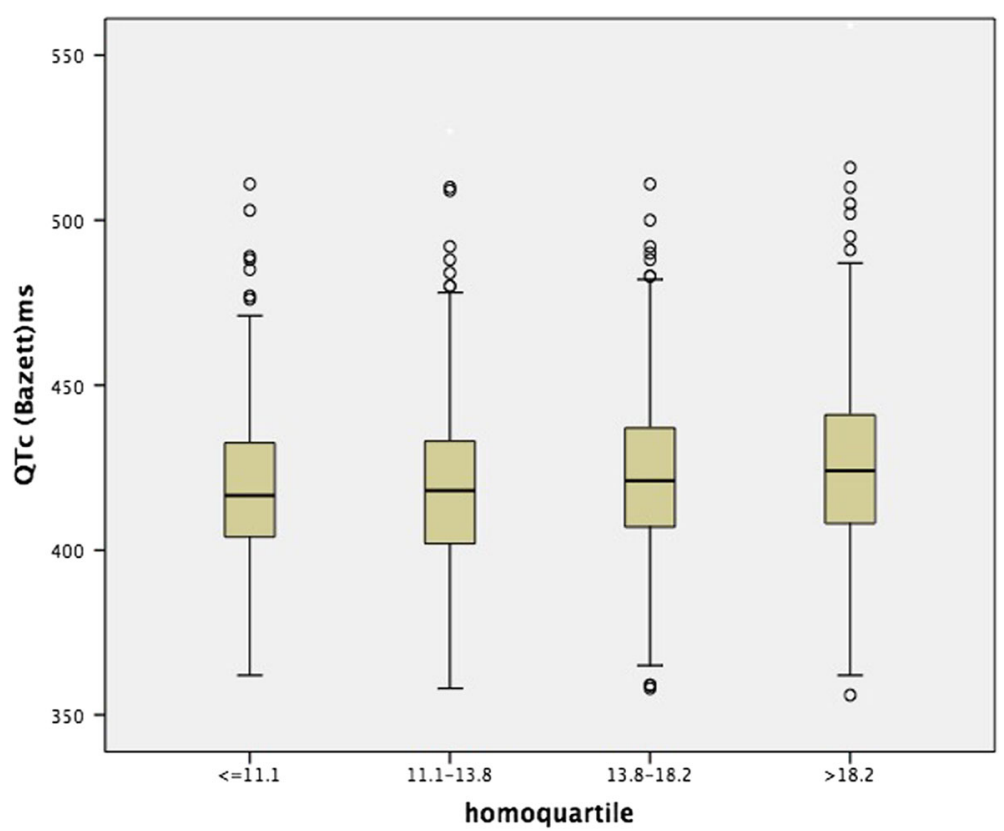

Fig. 1 The QTc intervals of males according to the Hcy quartiles

and fourth quartile increased $(P<0.05)$, and the OR was 1.23 (95\% CI: $1.05-1.43)$ for Q1 and 1.40 (95\% CI: 1.19-1.65) for Q4.

In the Additional file 2, we presented the result from linear regression analyses for association between homocysteine and QTc interval.

\section{Discussion}

In the present study, we evaluated the relationship of different Hcy levels to the QTc interval in the general population. We found that the odds for QTc $>440 \mathrm{~ms}$ in the first and fourth quartile of the Hcy level increased compared with those in the second quartile.

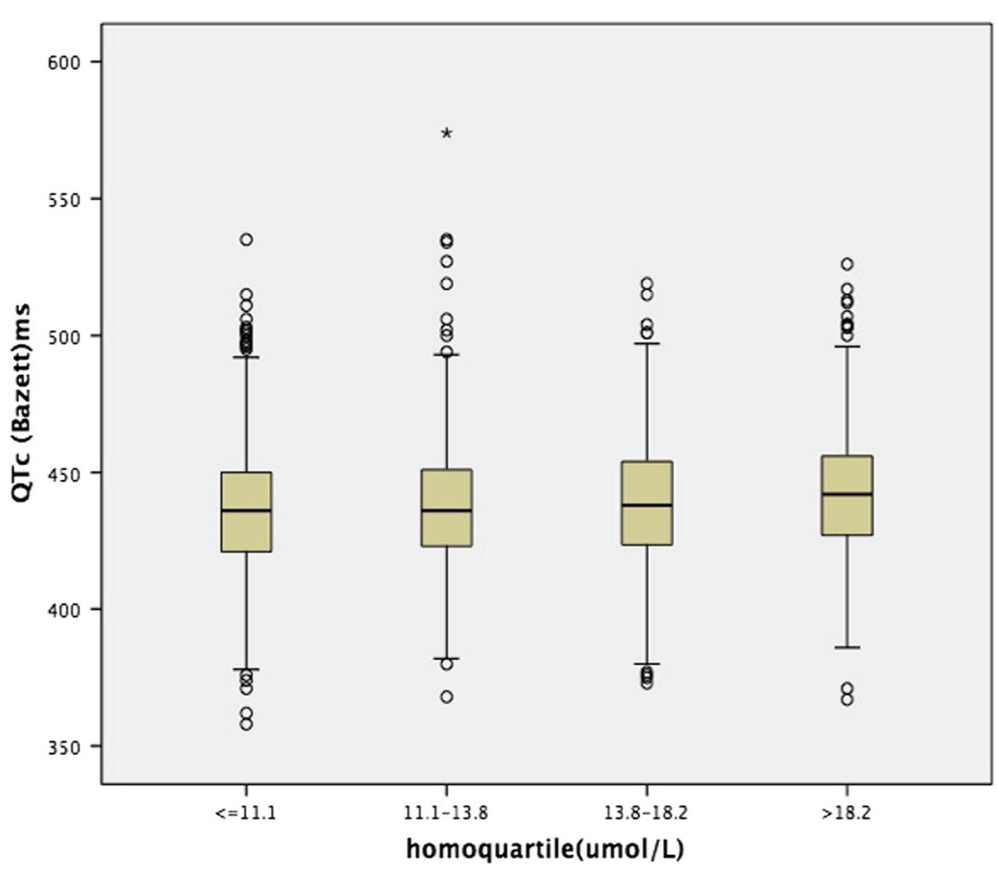

Fig. 2 The QTC intervals of females according to the Hcy quartiles 


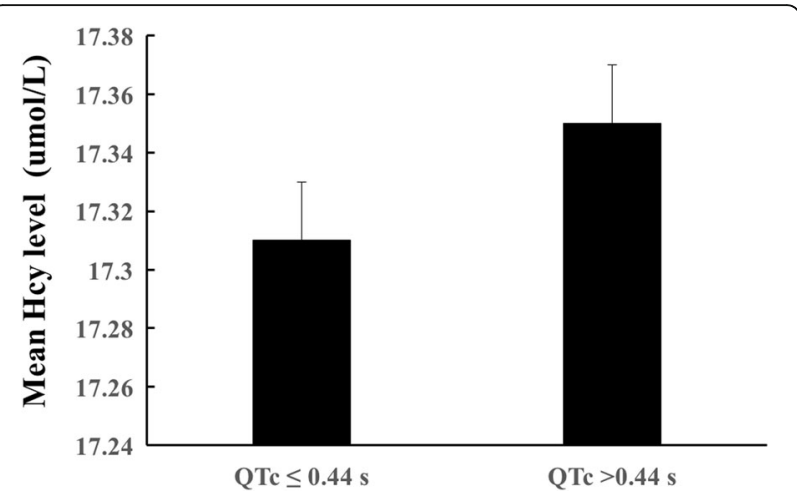

Fig. 3 Mean Hcy levels in participants with QTc $\leq 440$ ms and QTc > $440 \mathrm{~ms}$

Prior studies explored the relationship between Hcy levels and arrhythmias. Duyuler et al. found an independent relationship among the iron status, Tp-e interval and Tp-e/QT ratios of elite sport players that were also not correlated with serum homocysteine levels [33]. Previous researchers also found that the homocysteine levels determined prior to electrical cardioversion could predict recurrence of AF after successful restoration of sinus rhythms [34]. However, few studies focused on the QTc interval. Rosenberger et al. found a highly significant prolongation of the QTc interval in male C57/BL6J mice that received standard rodent chow and drinking water supplemented with $400 \mathrm{mg}$ DL-homocysteine compared with the controls, which received standard rodent chow and water ad libitum [11]. Acampa et al. measured Hcy plasma levels, P wave dispersions (PWD), and the QTc interval in 32 patients who had orthotropic heart transplantation (OHT) and in 20 control subjects. Acampa found that, in OHT patients, plasma Hcy levels significantly correlated with PWD, whereas no correlation was found with the QTc interval [13]. Lee Yin Leng et al. concluded that in community populations, homocysteine was moderately elevated when QRS durations were $>120 \mathrm{~ms}$, but QTc intervals were not significantly associated with plasma homocysteine [26]. In our study, Linear regression and multiple logistic regression analyses results showed an association between QTc interval and Hcy levels. Similar to other studies in China [35], we obtained the elevated average level of Hcy in this general population. Some studies reported a high prevalence of HHCY in Chinese populations, and smoking status, alcohol consumption, education level, physical activity and MTHFR genotypes were significant determinants. These factors also may explain the high levels of Hcy in this study.

To the best of our knowledge, this study is the first to demonstrate a correlation between Hcy levels and the QTc interval in a general population. Our results confirmed that a link exists between Hcy levels and cardiac electrophysiology. However, the mechanism of Hcymediated cardiac arrhythmias is still unclear. According to laboratory studies, elevations in Hcy levels can inhibit cardiac $\mathrm{K} 1$ channels, which may delay ventricular repolarization $[8,36]$. Homocysteine may decrease the $\mathrm{Na}+$ channel activity in in vitro cardiac preparations [9, 37-39]. Moreover, biochemical damage from high homocysteine levels on the atrial extracellular matrix involves the activation of matrix metalloproteinases-9 and extracellular signal regulated kinase and causes subsequent atrial fibrosis with slow and a heterogeneous atrial conduction, favoring the appearance of a vulnerable reentrant substrate [40-42]. However, these results do not explain the link between Hcy levels and the QTc interval. Therefore, future research is needed regarding this relationship. In addition, research is necessary to identify a mechanism that explains how both higher and lower levels of Hcy affect the QTc interval.

Our study had some limitations. First, we sampled adults only in the Liaoning Province, and could expect varying results if we had sampled adults in other Chinese provinces. Second, electrocardiograms for the participants were performed at one time, which may have affected our results. In addition, our results were based on a crosssectional design, and thus no cause-and-effect relationships could be established. Longitudinal studies are required for further investigation of these findings.

Table 3 Multivariable logistic regression analyses for association between homocysteine and long QTc interval

\begin{tabular}{|c|c|c|c|c|c|c|c|c|c|c|c|c|}
\hline \multirow{2}{*}{$\begin{array}{l}\text { Homocysteine } \\
\text { (quartiles) }\end{array}$} & \multicolumn{3}{|c|}{ Model 1} & \multicolumn{3}{|c|}{ Model 2} & \multicolumn{3}{|c|}{ Model 3} & \multicolumn{3}{|c|}{ Model 4} \\
\hline & OR & $95 \% \mathrm{Cl}$ & $P$-value & OR & $95 \% \mathrm{Cl}$ & $P$-value & OR & $95 \% \mathrm{Cl}$ & $P$-value & OR & $95 \% \mathrm{Cl}$ & $P$-value \\
\hline $\mathrm{Q} 1(\leq 11.1)$ & 1.205 & $1.038-1.399$ & 0.014 & 1.196 & $1.030-1.390$ & 0.019 & 1.203 & $1.031-1.404$ & 0.019 & 1.226 & $1.049-1.432$ & 0.010 \\
\hline Q2 (>11.1 and $\leq 13.8)$ & & \multicolumn{2}{|c|}{1.000 (reference) } & & \multicolumn{2}{|c|}{1.000 (reference) } & & \multicolumn{2}{|c|}{1.000 (reference) } & & \multicolumn{2}{|c|}{1.000 (reference) } \\
\hline Q3 (>13.8 and $\leq 18.2)$ & 1.135 & $0.974-1.323$ & 0.104 & 1.133 & $0.972-1.321$ & 0.110 & 1.134 & $0.969-1.326$ & 0.117 & 1.128 & $0.963-1.321$ & 0.137 \\
\hline Q4 (>18.2) & 1.504 & $1.287-1.758$ & $<0.001$ & 1.486 & $1.270-1.739$ & $<0.001$ & 1.408 & $1.197-1.656$ & $<0.001$ & 1.398 & $1.187-1.646$ & $<0.001$ \\
\hline
\end{tabular}

Model 1: adjusted for age, sex and race

Model 2: adjusted for factors in model 1 and education level, family income, dietscore, sleep duration, current smoking, drinking status, and physical activity Model 3: adjusted for factors in model 2 and and body mass index, waist circumference, systolic blood pressure, diastolic blood pressure, total cholesterol triglyceride, low-density lipoprotein cholesterol, high-density lipoprotein cholesterol, fasting plasma glucose

Model 4: adjusted for factors in model 3 and serum calcium, potassium and magnesium, history of heart disease and any medication Abbreviations: QTc corrected QT, OR odds ratio, 95\% Cl 95\% confidence interval 
And, in this study we used $440 \mathrm{mms}$ as the cut off, we agree with that opinion that dichotomization is debatable and variability of inter observer cannot be completely avoided. However, the linear regression gave the similar result. In this paper we can only present an association between homocysteine levels and QTc but can't conclude the correlation between homocysteine and prolonged QTc. Finally, beats with arrhythmias including AV-blocks were not deleted from QT measurements. Even though we used the heart rate with the correct QT interval, the effects of irregular heart rates could not be avoided.

\section{Conclusion}

In this general population, Hcy levels are associated with the QTc interval. The result provides novel, populationbased evidence of the relationship between Hcy levels and the QTc interval.

\section{Additional files}

Additional file 1: Supplementary flow chart. Baseline data from each participant with a final sample size of 7002 (3260 men and 3742 women). (DOC $41 \mathrm{~kb}$ )

Additional file 2: Linear regression analyses for association between homocysteine and QTc interval. Linear regression analyses presented the result that homocysteine is associated with QTc interval. (DOCX $69 \mathrm{~kb}$ )

\section{Abbreviations}

BMl: body mass index; CVD: cardiovascular disease; DBP: diastolic blood pressure; Hcy: Homocysteine; QTc: corrected QT; SBP: systolic blood pressure; SCD: sudden cardiac death.

\section{Acknowledgements}

Here, I would like to express my sincere thanks to all the authors. The authors would like to thank Professor Yingxian Sun who was responsible for the project completion.

\section{Funding}

This study was supported by grant from the "Twelfth Five-Year" project funds (National Science and Technology Support Program of China, Grant No. 2012BAJ18B02) and the fund assisted in data collection. This study was also supported by grant from the Natural Science Foundation of Liaoning Province (2013021090) and the fund assisted in manuscript writing.

\section{Availability of data and materials}

All the data supporting our findings have been presented in tables of this article. This is a series of studies, and the cohort study of this population is under way, so this part of the original data is not publicly disclosed at present stage. All the data supporting our findings have been presented in tables of this article.

\section{Authors' contributions}

ZL, XFG, GZX, LQZ and YXS made substantial contributions to design of this study and analysis of the data. ZL, XFG, GZX, LQZ and YXS involved in drafting the manuscript, gave final approval of the version to be published and agreed to be accountable for all aspects of the work. LQZ, YML, YXS and MRA took responsible for acquisition of data, revising it critically for important intellectual content. LQZ, YML, YXS and MRA gave final approval of the version to be published, and agreed to be accountable for all aspects of the work in ensuring that questions related to the accuracy or integrity of any part of the work are appropriately investigated and resolved.

\section{Ethics approval and consent to participate}

The study was approved by the Ethics Committee of China Medical University (Shenyang, China). All procedures were performed in accordance with ethical standards. Written consent was obtained from all participants after they had been informed of the objectives, benefits, medical items and confidentiality agreement regarding their personal information. For participants who were illiterate, we obtained written informed consent from their proxies.

\section{Consent for publication}

Consent for publication was obtained in all participants.

\section{Competing interest}

The authors declare that they have no competing interests.

\section{Publisher's Note}

Springer Nature remains neutral with regard to jurisdictional claims in published maps and institutional affiliations.

\section{Author details}

${ }^{1}$ Department of Cardiology, the First Hospital of China Medical University, 155 Nanjing North Street, Heping District, Shenyang 110001, People's Republic of China. 'Department of Clinical Epidemiology, Library, Shengjing Hospital of China Medical University, Shenyang, Liaoning, People's Republic of China. ${ }^{3}$ Department of Cardiology, Johns Hopkins University, Baltimore, MD, USA.

Received: 12 June 2016 Accepted: 27 June 2017

Published online: 11 July 2017

\section{References}

1. Nygård O, Vollset SE, Refsum H, Stensvold I, et al. Total plasma homocysteine and cardiovascular risk profile. The Hordaland Homocysteine Study JAMA. 1995;274(19):1526-33.

2. Xanthakis $V$, Enserro DM, Murabito JM, et al. Ideal cardiovascular health: associations with biomarkers and subclinical disease and impact on incidence of cardiovascular disease in the Framingham offspring study. Circulation. 2014;130(19):1676-83.

3. Reaven G. Raising the pressure on hypertension. Lancet. 2013;382(9887):126-7.

4. Nasir K, Tsai M, Rosen BD, et al. Elevated homocysteine is associated with reduced regional left ventricular function: the Multi-Ethnic Study of Atherosclerosis. Circ. 2007;115(2):180-7.

5. Verdoia M, Schaffer A, Pergolini $P$, et al. Homocysteine Levels Influence Platelet Reactivity in Coronary Artery Disease Patients Treated With Acetylsalicylic Acid. J Cardiovasc Pharmacol. 2015;66(1):35-40.

6. Pakfetrat M, Shahroodi JR, Zolgadr AA, et al. Effects of zinc supplement on plasma homocysteine level in end-stage renal disease patients: a doubleblind randomized clinical trial. Biol Trace Elem Res. 2013;153(1-3):11-5.

7. Fu Z, Qian G, Xue H, et al. Hyperhomocysteinemia is an independent predictor of long-term clinical outcomes in Chinese octogenarians with acute coronary syndrome. Clin Interv Aging. 2015;10:1467-74.

8. Shontz RD, Xu Z, Patel KP, et al. Inhibition of K+ currents by homocysteine in rat ventricular myocytes. J Cardiovasc Electrophysiol. 2001;12(2):175-82.

9. Pacher $P$, Ungvari Z, Kecskemeti V. Electrophysiological effects of homocysteine in isolated rat right ventricular papillary muscles and left atria. Gen Pharmacol. 1999:32:439-43.

10. Wenzel Seifert K, Wittmann M, Haen E. QTC prolongation by psychotropic drugs and the risk of torsade de pointes. Dtsch Arztebl Int. 2011;108(41):687-93.

11. Rosenberger D, Gargoum R, Tyagi N, et al. Homocysteine enriched diet leads to prolonged QT interval and reduced left ventricular performance in telemetric monitored mice. Nutr Metab Cardiovasc Dis. 2011:21(7):492-8.

12. Upadhya B, Ntim W, Brandon Stacey R, et al. Prolongation of QTc interval and risk of death among patients with sickle cell disease. Eur J Haematol. 2013;91(2):170-8.

13. Acampa M, Lazzerini PE, Guideri F, et al. Homocysteine and $P$ wave dispersion in patients with heart transplantation. Clin Transpl. 2011;25(1):119-25.

14. Munjal C, Tyagi N, Lominadze D, et al. Matrix metalloproteinase-9 in homocysteine-induced intestinal microvascular endothelial paracellular and transcellular permeability. J Cell Biochem. 2012;113(4):1159-69. 
15. Moshal KS, Metreveli N, Frank I, et al. Mitochondrial MMP activation, dysfunction and arrhythmogenesis in hyperhomocysteinemia. Curr Vasc Pharmacol 2008; 6(2):84-92. Review. .

16. Panoulas VF, Toms TE, Douglas KM, et al. Prolonged QTc interva predicts all-cause mortality in patients with rheumatoid arthritis: an association driven by high inflammatory burden. Rheumatology (Oxford). 2014;53(1):131-7.

17. Nielsen JB, Graff C, Rasmussen PV, et al. Risk prediction of cardiovascular death based on the QTc interval: evaluating age and gender differences in a large primary care population. Eur Heart J. 2014;35(20):1335-44.

18. Selker HP, Raitt MH, Schmid CH, et al. Time-dependent predictors of primary cardiac arrest in patients with acute myocardial infarction. Am J Cardiol. 2003;91(3):280-6.

19. Lai CC, Hsiao HC, Hsiao SH, et al. Role of shortened QTC dispersion in in-hospital cardiac events in patients undergoing percutaneous coronary intervention for acute coronary syndrome. J Chin Med Assoc. 2006;69(7):297-303.

20. Li Z, Guo X, Chen S, et al. Hyperhomocysteinemia independently associated with the risk of hypertension: a cross-sectional study from rural China. J Hum Hypertens. 2015; 9:1-5.

21. Sun GZ, Guo L, Wang XZ, Song HJ, Li Z, Wang J, Sun YX. Prevalence of atrial fibrillation and its risk factors in rural China: a cross-sectional study. Int J Cardiol. 2015;26:13-7.

22. Guo X, Li Z, Sun G, et al. Comparison of four nontraditional lipid profiles in relation to ischemic stroke among hypertensive Chinese population. Int J Cardiol. 2015;201:123-5.

23. Sun GZ, Guo L, Wang XZ, et al. Prevalence of atrial fibrillation and its risk factors in rural China: a cross-sectional study. Int J Cardiol. 2015;182:13-7.

24. Panagiotakos DB, Pitsavos C, Chrysohoou C, et al. Epidemiology of overweight and obesity in a Greek adult population: the ATTICA study. Obes Res. 2004;12:1914-20.

25. O'Brien E, Petrie J, Littler W, et al. The British hypertension society protocol for the evaluation of automated and semi-automated blood pressure measuring devices with special reference to ambulatory systems. J Hypertens. 1990:8:607-19.

26. Leng YLY, Zhou Y, Ke H, et al. Electrocardiogram derived QRS duration> 120 $m s$ is associated with elevated plasma homocysteine levels in a rural Australian cross-sectional population[J]. Medicine. 2015;94(27):1-5.

27. Bazett HC. An analysis of the time relations of electrocardiograms. Heart. 1920;7:353-67.

28. Sagie A, Larson MG, Goldberg RJ, et al. An improved method for adjusting the QT interval for heart rate (the Framingham heart study). Am J Cardiol. 1992;70(7):797-801.

29. Fridericia LS. EKG systolic duration in normal subjects and heart disease patients. Acta Med Scand. 1920;53:469-88.

30. Schwartz PJ, Moss AJ, Vincent GM, et al. Diagnostic criteria for the long QT syndrome. An update Circulation. 1993;88(2):782-4.

31. Akintunde AA1, Oyedeji AT, Familoni OB, et al. QT Interval prolongation and dispersion: Epidemiology and clinical correlates in subjects with newly diagnosed systemic hypertension in Nigeria. J Cardiovasc Dis Res. 2012;3:290-5.

32. Neyroud N, Maison-Blanche P, Denjoy I, et al. Diagnostic performance of QT interval variables from 24-h electrocardiography in the long QT syndrome. Eur Heart J. 1998;19:158-65.

33. Duyuler $\mathrm{S}$, Türker Duyuler $\mathrm{P}$, Batur MK. Impact of iron and homocysteine levels on T peak-to-end interval and Tp-e/QT ratio in elite athletes. Ann Noninvasive Electrocardiol. 2016; doi:10.1111/anec.12365. [Epub ahead of print]

34. Naji F, Suran D, Kanic V, et al. High homocysteine levels predict the recurrence of atrial fibrillation after successful electrical cardioversion. Int Heart J. 2010;51(1):30-3.

35. Liu XD, Gao B, Sun D, et al. Prevalence of hyperhomocysteinaemia and some of its major determinants in Shaanxi Province, China: a cross-sectional study. Br J Nutr. 2015;113(4):691-8. doi:10.1017/S0007114514004218. Epub 2015 Jan 30

36. Marcucci R, Betti I, Cecchi E, et al. Hyperhomocysteinemia and vitamin B6 deficiency: new risk markers for nonvalvular atrial fibrillation? Am Heart J. 2004;148(3):456-61.

37. Cai BZ, Gong DM, Liu Y, et al. Homocysteine inhibits potassium channels in human atrial myocytes. Clin Exp Pharmacol Physiol 2007;34(9):851-855. PubMed.

38. Cai B, Gong D, Pan Z, et al. Large-conductance Ca2+-activated K+ currents blocked and impaired by homocysteine in human and rat mesenteric artery smooth muscle cells. Life Sci. 2007;80(22):2060-6.
39. Hamed SA, Nabeshima T. The high atherosclerotic risk among epileptics: the atheroprotective role of multivitamins. J Pharmacol Sci 2005;98(4):340-353 Review.

40. Cai B, Shan L, Gong D, et al. Homocysteine modulates sodium channel currents in human atrial myocytes. Toxicology. 2009;256(3):201-6.

41. Twardowski T, Jakubowski H. Mechanisms of homocysteine toxicity in humans[J]. Amino Acids. 2007;32(4):561-72.

42. Acampa M, Lazzerini PE, Guideri F, et al. Ischemic stroke after heart transplantation. Journal of stroke. 2016;2:1-12.

\section{Submit your next manuscript to BioMed Central and we will help you at every step:}

- We accept pre-submission inquiries

- Our selector tool helps you to find the most relevant journal

- We provide round the clock customer support

- Convenient online submission

- Thorough peer review

- Inclusion in PubMed and all major indexing services

- Maximum visibility for your research

Submit your manuscript at www.biomedcentral.com/submit 